\title{
Sequence to Structure Approach of Estrogen Receptor Alpha and Ligand Interactions
}

\author{
Aekkapot Chamkasem ${ }^{1}$, Waraphan Toniti²*
}

\begin{abstract}
Estrogen receptors (ERs) are steroid receptors located in the cytoplasm and on the nuclear membrane. The sequence similarities of human $\mathrm{ER} \alpha$, mouse $\mathrm{ER} \alpha$, rat $\mathrm{ER} \alpha, \operatorname{dog} \mathrm{ER} \alpha$, and cat $\mathrm{ER} \alpha$ are above $90 \%$, but structures of ER $\alpha$ may different among species. Estrogen can be agonist and antagonist depending on its target organs. This hormone play roles in several diseases including breast cancer. There are variety of the relative binding affinity (RBA) of ER and estrogen species in comparison to 17 $\beta$-estradiol (E2), which is a natural ligand of both ER $\alpha$ and ER $\beta$. The RBA of the estrogen species are as following: diethyl stilbestrol (DES) $>$ hexestrol $>$ dienestrol $>$ 17 $\beta$-estradiol $($ E2) $>$ 17- estradiol $>$ moxestrol $>$ estriol $($ E3) $>4-O H$ estradiol $>$ estrone-3-sulfate. Estrogen mimetic drugs, selective estrogen receptor modulators (SERMs), have been used as hormonal therapy for ER positive breast cancer and postmenopausal osteoporosis. In the postgenomic era, in silico models have become effective tools for modern drug discovery. These provide three dimensional structures of many transmembrane receptors and enzymes, which are important targets of de novo drug development. The estimated inhibition constants (Ki) from computational model have been used as a screening procedure before in vitro and in vivo studies.
\end{abstract}

Keywords: ER $\alpha$ - in silico model - SERMs - binding affinity

Asian Pac J Cancer Prev, 16 (6), 2161-2166

\section{Estrogen Receptors and Estrogen}

Estrogen receptors (ERs) are members of 7-transmembrane receptors such as steroid hormone receptor subfamily, $\mathrm{G}$ protein coupled receptor family, and nuclear hormone receptor superfamily. The amino acid sequences are different in types and depend on species (Kumar and Thompson, 1999; Kumar et al., 2011). There are two subtypes of estrogen receptor; ER $\alpha$ and ER $\beta$ (Kuiper et al., 1997; Barkhem et al., 1998). The genes encoding ERs located on different chromosomes, which are species specific. For example, ER $\alpha$ locates on chromosome 6th and ER $\beta$ on chromosome 14th in humans. In mice, $E R \alpha$ are on the 10th and ER $\beta$ on the 12th whereas ER $\alpha$ locates on the 1st and $\operatorname{ER} \beta$ on the 6th in rats. $\operatorname{ER} \alpha$ are on the 1 st and $E R \beta$ on the 2 nd in $\operatorname{dog}$ comparison to $\mathrm{ER} \alpha$ on $\mathrm{B} 2$ and $\mathrm{ER} \beta$ on $\mathrm{B} 3$ in cat.

ERs consist of 5 domains; 1$) \mathrm{N}$-terminal domain (NTD), 2) DNA binding domain (DBD), 3) Hinge region, 4) Ligand binding domain (LBD), and 5) Agonistantagonist distinct (C-terminal domain) (Lewis et al., 2002; Kumar et al., 2011). ERs-ligands interaction are attributed to changing LBD conformation. The binding affinity is calculated by measurement of the strength of the interaction between LBD and such ligands via computational technique.

The ERs-unliganded usually circulate in the cytoplasm, while the ERs-liganded expand on the nuclear membrane (Rybalchenko et al., 2009). ERs also distribute in varieties of reproductive organs. Expressions of ER $\alpha$ are found abundantly in normal organs such as uterus, liver, vagina and pituitary (Kuiper et al., 1997; Osborne et al., 2000; Millanta et al., 2005; Illera et al., 2006). On the other hand, the expressions of ER $\beta$ are found in ovary, prostate, epididymis, lung, and hypothalamus (Frasor et al., 2003). ERs bind to estrogen then induce conformational change and downstream cascades.

Estrogen involves in RNA synthesis, the expression of co-activators and/or co-repressors, and several protein synthesis. This steroid hormone also regulates ovarian follicles growth, mammary gland development, and female fertility.

\section{From Sequence to Structure}

ER comprises of 10 to $12 \alpha$-helical elements link to another by short loop. Ligand binding domain is non-polar hydrophobic pocket site, which is selectively bind ligands (Anstead et al., 1997; Pike et al., 1999).

Nowadays, protein crystallization technique and x-ray

${ }^{1}$ Faculty of Veterinary Science, Mahidol University, ${ }^{2}$ Department of Pre-clinic and Applied Animal Sciences, Faculty of Veterinary Science, Mahidol University, Salaya, Nakhon-Pathom, Thailand*For correspondence: waraphan.ton@mahidol.edu 
crystallography are applied to the study of macromolecular research especially DNA and protein structure. Amino acid sequences and protein structures are published on several protein data bank (PDB) for example; European Bioinformatics Institute (EBI-PDBe), Research Collaboratory for Structural Bioinformatics (RSBC-PDB).

\section{Sequence Identity and Structure Comparisons}

The sequence alignment is a well-known method. The particular amino sequences are selected from protein database in * fasta file type. Results of multiple sequence alignment represent as the identity score and phylogenetic tree, which imply the similarity of sequences (Ascenzi et al., 2006; Leinonen et al., 2006; Gaudet et al., 2009; Sievers et al., 2011). The sequence similarities indicate the functional, structural, and phylogenetic relationships between the sequences (Larkin et al., 2007).

\section{Similarity between ER $\alpha$ and ER $\beta$ in Man}

The amino acid sequences of human $\mathrm{ER} \alpha$ (NP_000116) and ER $\beta$ (NP_001428) are selected from protein database. Both of them have been compared by Clustal W (Thompson et al., 1994; Ascenzi et al., 2006). ER $\alpha$ and ER $\beta$ are partial identity. Previously mentioned, ERs and steroid hormone receptors compose of 5 functional domains (Figure 1).

With a transactivation function, N-terminal domain (A/B) is high variation region and shows less than $20 \%$ identity (Table 1). DNA binding domain (C) binds to specific a DNA-binding region and plays important role in receptor dimerization. There are highly similarity between $\mathrm{hER} \alpha$ and $\mathrm{hER} \beta$, which are sharing greater than $94 \%$ identity. Hinge region (D) consists of flexible region and DBD-LBD linkage. Ligand binding domain (E) is specific for ligand binding site, receptor dimerization, nuclear localization and transcriptional co-activators/co-repressors binding. The LBD of $h E R \alpha$ and $h E R \beta$ is partial identity; approximately $55 \%$ identity. This suggests that there are variation of ligand binding sites among ERs (Lewis et al., 2002; Kumar et al., 2011).

C-terminal domain $(\mathrm{F})$, the lowest identity region, contributes to the transactivation capacity of the receptor.
ERs may interact with estrogen species such as Estradiol (E2), Diethylstilbestrol (DES), etc. Moreover, gene activation is induced by promoter, cell-specific factors, and by synergistic interaction between the $\mathrm{N}$-terminal domain and $\mathrm{C}$ - terminal receptor activation domains. This suggests that receptors may change their function due to mutation of $\mathrm{N}$-terminal domain and $\mathrm{C}$-terminal region

\section{Similarity of ER $\alpha$ in Human, Rat, Mouse, Dog and Cat}

The comparison of identity scores of human ER $\alpha$, mouse $\mathrm{ER} \alpha$, rat $\mathrm{ER} \alpha, \operatorname{dog} \mathrm{ER} \alpha$, and cat $\mathrm{ER} \alpha$ are shown in Table 2. The identity scores are $97.2 \%$ in mouse, $96.7 \%$ in rat, $94.6 \%$ in dog, and $95.5 \%$ in cat. Moreover, LBD are highly similar among species of interest. Variety of amino acid sequences result in the diversity of tertiary protein structures (Figure 2). Also, the variation of structure shows that structure-based design drugs for human being may not be appropriate used for treatment of all animal species.

\section{Tertiary Structure of ER $\alpha$}

Basically, ER $\alpha$ forms homodimer in activated stage. The interactions of the monomers are hydrogen bonds between the N-terminal portion of helix 10/11 and helix 9 , which is divided to 3 regions (Figure 3 ). The antiparallel configuration of $\mathrm{ER} \alpha$ interacts at specific motifs: DKITD and QQQHQRLAQ. Another, the parallel binding of monomer A and monomer B interacts at LSHIRHMSNK motifs. The interaction energy and bond length of ER $\alpha$ -

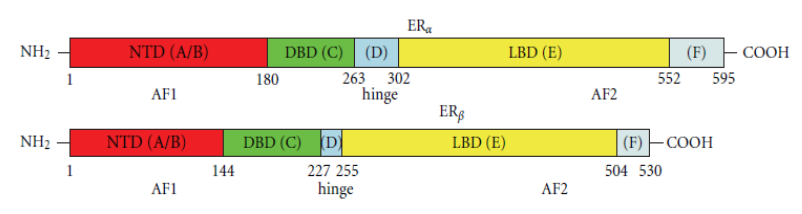

Figure 1. Functional domains of two isoforms of estrogen receptors. Colors represent each domain: N-terminal domain (Red), DNA-binding domains (Green), Hinge region (Blue), Ligand binding domain (Yellow), and C-terminal end (Grey) (Kumar et al., 2011)

Table 1. Amino Acid Sequence Identity Score (\%) of hER $\alpha$ and hER $\beta$

\begin{tabular}{|c|c|c|c|c|c|c|c|}
\hline & \multicolumn{7}{|c|}{ Sequence Identity Score (\%) } \\
\hline & Full length & Length (residue) & NTD & DBD & Hinge Region & LBD & $\begin{array}{c}\text { C-terminal } \\
\text { Domain }\end{array}$ \\
\hline $\mathrm{hER}^{\mathrm{a}}$ & 595 & $44^{\mathrm{a}, \mathrm{b}}$ & $\begin{array}{l}12^{\mathrm{a}} \\
15^{\mathrm{c}}\end{array}$ & $96^{\mathrm{a}, \mathrm{b}, \mathrm{c}}$ & $16^{\mathrm{a}}$ & $\begin{array}{l}55^{\mathrm{a}} \\
56^{\mathrm{b}}\end{array}$ & $9^{a}$ \\
\hline $\mathrm{hER}^{\mathrm{b}}$ & 530 & & $<20^{b}$ & & & $59^{a}$ & \\
\hline
\end{tabular}

${ }^{\mathrm{a} A s c e n z i}$ et al., 2006, ${ }^{\mathrm{b}}$ Matthew and Lo, 2010, ${ }^{\mathrm{c}}$ Kumar et al., 2011

Table 2. LBD Identity Score (\%) of Human ER $\alpha$, Mouse ER $\alpha$, Rat ER $\alpha$, Dog ER $\alpha$, and Cat ER $\alpha$

\begin{tabular}{|c|c|c|c|c|c|}
\hline ER-a & Human & Mouse & Rat & Dog & Cat \\
\hline Identity (\%) & 100 & 97.2 & $96.7^{\mathrm{d}}$ & $94.6^{\mathrm{c}}$ & $95.5^{c}$ \\
\hline Length (residue) & $595^{\mathrm{a}}$ & $599^{b}$ & $600^{\mathrm{b}}$ & $596^{c}$ & $595^{\mathrm{c}}$ \\
\hline
\end{tabular}

${ }^{\mathrm{a}}$ Maggiolini et al., 2001, ${ }^{\mathrm{b}}$ Bollig-Fischer et al., 2012, ${ }^{\mathrm{c}}$ Toniti et al., 2011, ${ }^{\mathrm{d}}$ Madeira et al., 2012 
ligands complex depend on the binding ligands; besides, water molecule in crystal structure stabilize the structural conformation (Brzozowski et al., 1997; LaFrate et al., 2009; Chakraborty et al., 2012).

\section{$\mathbf{E R} \alpha$-ligand Interactions}

The fairy tale of ER $\alpha$-ligand interaction began whenever protein purification and X-ray crystallography became popular among structural biologists. According to PDB codes, 1ERE represents the interaction between $\mathrm{ER} \alpha$ and it natural ligand, E2. This ER $\alpha: \mathrm{E} 2$ complex is modified all cysteine residues by carboxymethylation. E2 closely binds to hydrophobic LBD through intermolecular forces; electrostatic force, van der Waals force, covalent bond and hydrogen bond. The pocket cavity is twice as large as E2 size. ER $\alpha$ pocket site composes of parts of Helix3 (M342 to L354), Helix6 (W383 to R394), Helix8 and the preceding loop (V418 to L428), Hexlix11 (M517 to M528), Helix 12 (L539 to H547) and the S1/S2 hairpin (L402 to L410) (Brzozowski et al., 1997). ER $\alpha$ interacts with phenolic hydroxyl group of E2 A-ring by E353 and R394 and interacts with hydroxyl group of E2 D-ring by $\mathrm{H} 524$ as shows in Figure 4 (Brzozowski et al., 1997; Meshram et al., 2012; Cao et al., 2013).

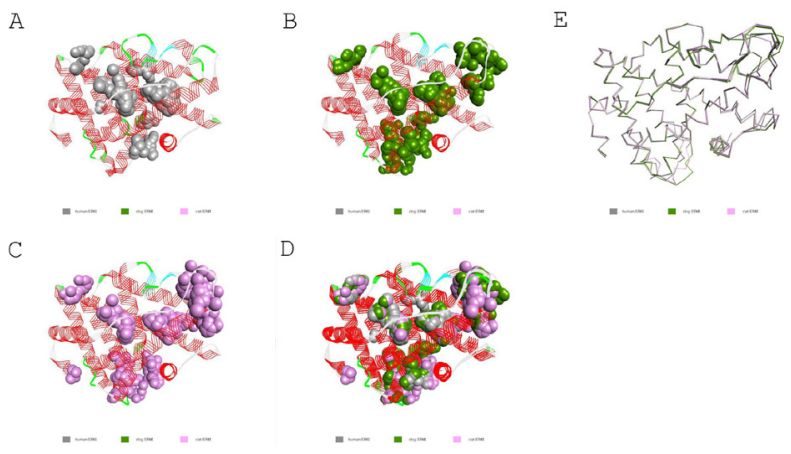

Figure 2. Tertiary Structure of the Selected ER $\alpha$. A) Human ER $\alpha$, B) $\operatorname{dog}$ ER $\alpha$, and C) cat ER $\alpha$. D) Superimposes of $E R \alpha$ structures with predicted pocket sites, E) Superimposes of the selected $E R \alpha$. Colors represent each species; human (Grey), $\operatorname{dog}$ (Green), and cat (Magenta). The Sequences of human, dog and cat ER $\alpha$ were selected from the Universal Protein Resource (UniProt) by P03372, F6V0I8, and Q53AD2, respectively. The PDB templates are generated by Sali Lab: Modweb; 3UUD for human $\mathrm{ER} \alpha$, and $2 \mathrm{QZO}$ for $\operatorname{dog} \mathrm{ER} \alpha$, and cat $\mathrm{ER} \alpha$ (Pieper et al., 2004; UniProt, 2014)
Naturally, estrogen may be agonist and/or antagonist, depending on target organs. There are a number of research groups publish PDB codes, which show variety of $\mathrm{ER} \alpha$ and its ligands interactions, for example, 3ERD (ER $\alpha$ :DES), 3ERT (ER $\alpha: 4 \mathrm{OHT})$. DES is non-steroidal estrogen agonist (Figure 5). According to the similarity between A-ring of DES and E2, thus A-ring of DES interacts with the same residues. Meanwhile, the A'-ring of DES interacts with H524 comparing to D-ring of E2 as shows in Figure 6.

3ERD comprises of 305-505 residues, however, there are some missing residues in monomer B (residue 462469). These missing residues play role in the dimerization of ER $\alpha$ homodimer. The nonpolar groups of DES interact with several side chains of A350, L384, F404, and L428, leading to highly binding affinity comparison to ER $\alpha$ :E2 interaction (Shiau et al., 1998; Nam et al., 2003; Chakraborty et al., 2012; Nam et al., 2012)

3ERT represents the binding of 4-hydroxytamoxifen (4OHT) A-ring to the side chains of E353, R394, and a structurally conserved water molecule. The 4OHT C-ring forms van der Waals force with M343, L346, T347, A350, W383, L384, L387, and L525. The 4OHT B-ring cannot bind to other residue properly, in spite of both E2 D-ring

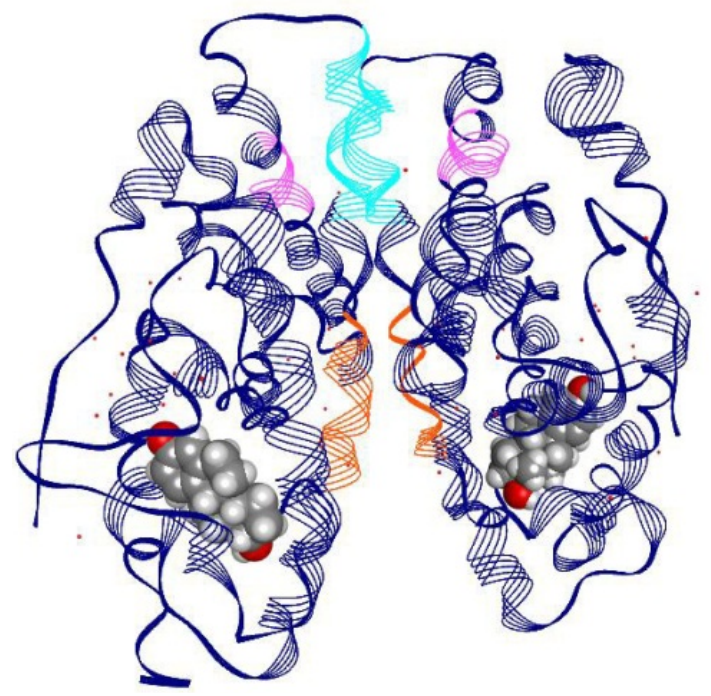

Figure 3. Homodimerization of $\mathrm{ER} \alpha$ Monomer A and B (1ERE). Colors depict the particular motifs involved in dimerization. Cyan (QQQHQRLAQ), Magenta (DKITD), and Orange (LSHIRHMSNK) (Brzozowski et al., 1997)

Table 3. Top Ten Ranking of the Estimated Inhibitor Constants (Ki) of Human ER $\alpha$, Dog ER $\alpha$, and Cat ER $\alpha$ (Toniti et al., 2011)

\begin{tabular}{llllllc}
\hline Rank & \multicolumn{2}{c}{ Human } & \multicolumn{1}{c}{ Dog } & \multicolumn{2}{c}{ Cat } \\
& \multicolumn{1}{c}{ Ligands } & $\mathrm{K}_{\mathrm{i}}(\mathrm{pM})$ & \multicolumn{1}{c}{ Ligands } & $\mathrm{K}_{\mathrm{i}}(\mathrm{pM})$ & \multicolumn{1}{c}{ Ligands } & $\mathrm{K}_{\mathrm{i}}(\mathrm{pM})$ \\
\hline 1 & Bazedoxifene & 52.80 & Neohesperidin Dihydrochalcone & 151.82 & Schreiber_2 & 25.79 \\
2 & Beta-carotene & 143.54 & Schreiber_2 & 168.05 & Tinyatoxin & 29.30 \\
3 & Arzoxifene & 178.58 & Beta-carotene & 248.65 & Beta-carotene & 31.18 \\
4 & Raloxifene & 188.35 & Remiszewski_013 & 340.90 & Leptomycin & 31.87 \\
5 & Lasofoxifene & 229.27 & Zafulukast & 476.40 & u-74389g & 37.72 \\
6 & Omeloxifene & 312.73 & Bisindoly maleimide II & 497.14 & Diosmin & 40.26 \\
7 & Chap16 & 363.97 & Bisindoly maleimide VI & 514.06 & Rutoside & 48.74 \\
8 & Chap1 & 545.69 & Baedoxifene & 689.49 & Colletti_14 & 70.36 \\
9 & Fortovase & 565.71 & Raloxifene & 747.21 & Indinavir & 108.70 \\
10 & Lovastatin & 614.60 & Homoharringtonine & 1050.00 & Calmidazolium chloride & 110.18 \\
\hline
\end{tabular}




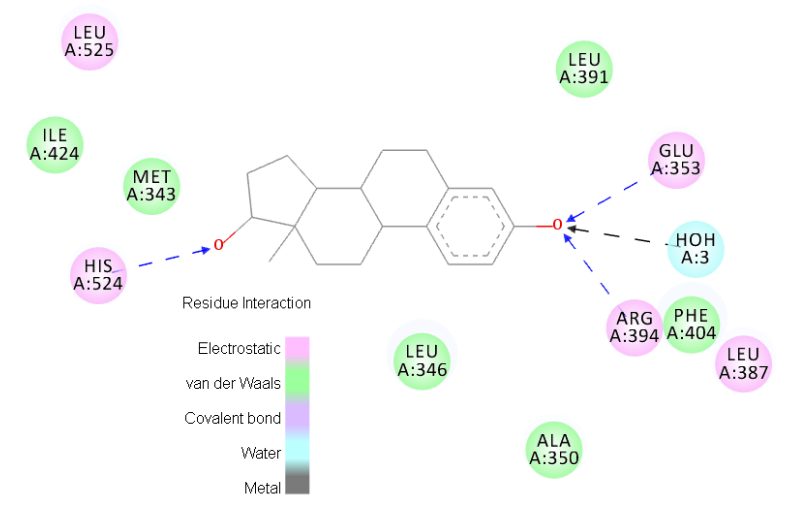

Figure 4. The interaction of ER $\mathrm{E}: \mathrm{E} 2$ shows in 2D

Pattern. Blue color and direction of the arrows depict hydrogen bond and the direction toward electron donor

A

$\mathrm{B}$
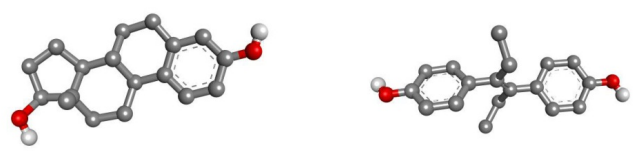

C

$17 \beta$-Estradiol $\left(E_{2}\right) \quad$ Diethyl stilbestrol (DES)

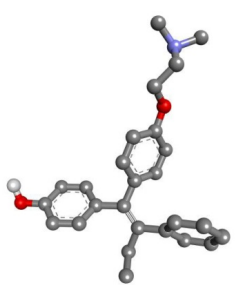

Hydroxytamoxifen

(40HT or 4-OH-TAM)

D

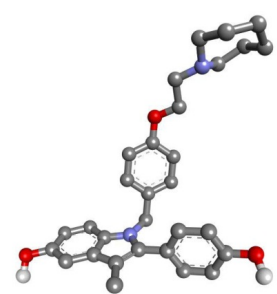

Bazedoxifene (BZA)

Figure 5. Three Dimension Structures of A) E2, B) DES, C) 4OH-Tamoxifen, and D) Bazedoxifene. The ligand structures are available from RCSB-Protein Data Bank and EMBL-European Bioinformatics Institute (Berman et al., 2000; Rustici et al., 2013)
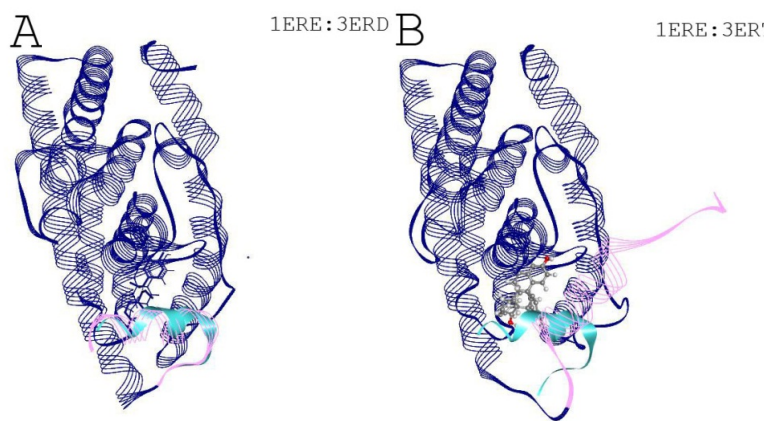

Figure 6. Superimposes of 1ERE and 3ERD, 1ERE and 3ERT. Colors represent each PDB; 1ERE (Cyan), 3ERD and 3ERT (Magenta). A) The agonist position of Helix 12 of 1ERE and 3ERD. B) The conformational change of H12 of 3ERT results in antagonistic effect (Brzozowski et al., 1997; Shiau et al., 1998)

and DES A'-ring can bind to H524 imidazole ring. In addition, the conformational change of Helix 12 disrupt the

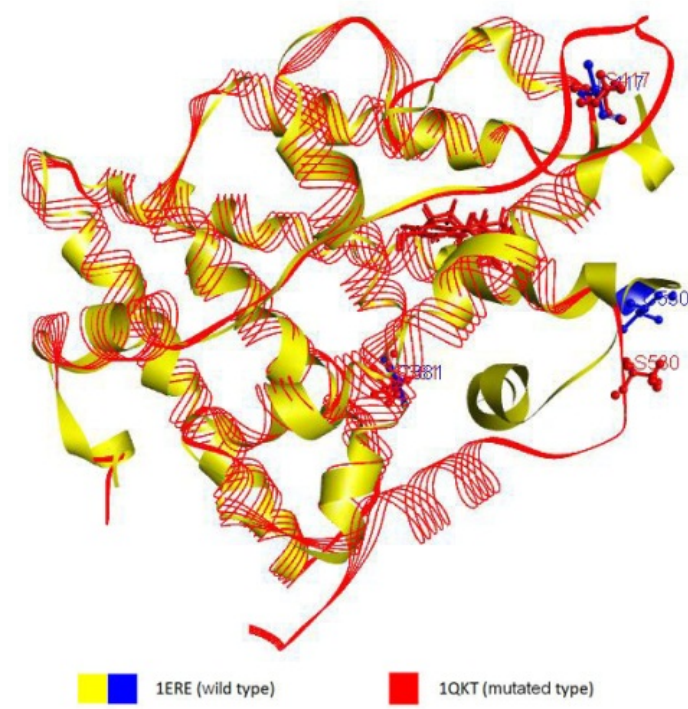

Figure 7. A) Superimpose Structure of 1ERE and 1QKT. Colors represent wild type and mutant; 1ERE (Yellow), 1QKT (Red), C381, C417 and C530 (Blue), and C381S, C417S and C530S (Red). (Brzozowski et al., 1997; Gangloff et al., 2001)

co-activator protein binding. The conformational change of Helix 12 position leads to inhibit the ER-DNA binding (Shiau et al., 1998).

Basic knowledge of the interaction between receptor and ligands provides information of structure-based drug design. The pharmacomimetic substances have been synthesized and studied for bioavailability, pharmacokinetic, drug clearance and so on. Moreover, compounds from the natural flavonoids are having antibreast cancer activity and also have no any side effects to human normal cell. For example, Crysin and Equol were found to have high binding energy to ER $\alpha, 2$ IOG (Suganya et al., 2014).

\section{ER $\alpha$ Mutagenesis}

ER $\alpha$-ligand complex undergoes conformational changes in association of variety of ligands. Furthermore, the mutation of ER $\alpha$ itself may play roles in the interaction between ER $\alpha$ and its ligands. For example, 1QKT, the mutant structure of triple cysteine residues (C381S, C417S, C530S). Comparison to 1ERE, 1QKT results in hydrogen bond disruption, Helix12 deposition, and shortening of Helix 3 and Helix 11 (Figure 7). Interestingly, 1QKT shows the interaction between carbonyl group of E353 and E2 A-ring, whereas hydrogen bond between D ring of E2 and amino acid residue is not found (Gangloff et al., 2001).

\section{Binding Affinity of ER $\alpha$ and its Ligands}

ERs comprise of 10 to $12 \alpha$-helical elements by each one is linked with a short loop structure. Naturally, ER may form homodimers and/or heterodimers ( $\mathrm{Li}$ et al., 2004). Both ER- $\alpha$ and ER- $\beta$ clusters are non-polar hydrophobic pocket. Estrogens are natural steroid and sex hormones: estrone (E1), estradiol (E2), and estriol (E3). 
The estrogenic effect regulates male and female such as growth, cardiovascular function, and obesity (Anstead et al., 1997; Arnal et al., 2012). Estrogens binding to ERs induce the conformational change of ERs. E2 is known as natural ligand of both ER $\alpha$ and ER $\beta$. The estrogenic effect of E2 is more potent than E1 and E3. Additionally, the binding affinity between ERs-E2 is higher than E1 and E3 in human and mammal (Kuiper et al., 1997).

Several terms perform to explain the receptors-ligands interaction. For example, Receptor Binding Affinity (RBA), free energy perturbation $\left(\triangle G_{\text {bind }}\right)$, dissociation constant $(\mathrm{Kd})$, and estimated inhibition constants (Ki) are used (Kuiper et al., 1997; Nose et al., 2009; Toniti et al., 2011). RBA of the estrogen species are as following: diethyl stilbestrol $($ DES $)>$ hexestrol $>$ dienestrol $>17-\beta$ estradiol $(E 2)>17$ - estradiol $>$ moxestrol $>$ estriol $(E 3)>$ 4-OH estradiol $>$ estrone-3-sulfate.

The good inhibitors tend to lower Ki (pM) (Schnell and Mendoza, 2001). The best inhibitor of human ER $\alpha$ is Bazedoxifene (Toniti et al., 2011). On the other hand, the best inhibitor of dog is Neohesperidin dihydrochalcone and in cat is Schreiber_2 (Table 3). Bazedoxifene is a third generation SERMs. It is agonist on bone though antagonist on mammary cell and uterine cell (Stump et al., 2007). Bazedoxifene is recently approved for treatment of in postmenopausal osteoporosis (de Villiers et al., 2013).

Beta-carotene ranks as top three in human, dog, and cat. The circulating carotenoid has been reported as an inverse relation to risk factors of breast cancer (Eliassen et al., 2012; Hendrickson et al., 2012). Betacarotene also suppresses ER-positive breast cancer cell proliferation (Czeczuga-Semeniuk et al., 2009; Zhang et al., 2012). SERMs have variety physiological functions depended on the target organ. For example, Raloxifen reduces vertebral facture risks and also uses as hormonal therapy in postmenopausal osteoporosis and breast cancer (Tremollieres and Lopes, 2002; Touraine, 2003; D'Amelio and Isaia, 2013).

However, human $\mathrm{ER} \alpha, \operatorname{dog} \mathrm{ER} \alpha$, and cat $\mathrm{ER} \alpha$ share partial identity of LBD. The alteration of ERs structures causes the conformational changes, thus it may affect the estrogenic function of E2 and SERMs in human, dog, and cat. Therefore, the estrogen mimetic drugs should be designed and developed more specifically to individual species (Schnell and Mendoza, 2001; Rehm et al., 2007; Toniti et al., 2011).

Furthermore, drug-likeness on the basis of "Lipinski's Rule of Five" and ADMET (absorption, distribution, metabolism, elimination, toxicity) have been recently set as a criterion for protein-drug designed trend. The high throughput virtual screening are extensively used to reduce cost and time of drug discovery (Chitrala and Yeguvapalli, 2013). It is significant that $\mathrm{ER} \alpha$ plays role in breast cancer diagnosis, treatment, and prognosis. However, it may involve in $\mathrm{ER} \alpha$-mediated drug resistance thus further study in this area is necessary (Xu et al., 2013).

\section{Acknowledgements}

The Illustrations were prepared by Discovery Studio 4.0 by Accelrys Software Inc.

\section{References}

Anstead GM, Carlson KE, Katzenellenbogen JA (1997). The estradiol pharmacophore: ligand structure-estrogen receptor binding affinity relationships and a model for the receptor binding site. Steroids, 62, 268-303.

Arnal JF, Valera MC, Payrastre B, et al (2012). Structurefunction relationship of estrogen receptors in cardiovascular pathophysiological models. Thromb Res, 130, 7-11.

Ascenzi P, Bocedi A, Marino M (2006). Structure-function relationship of estrogen receptor alpha and beta: impact on human health. Mol Aspects Med, 27, 299-402.

Barkhem T, Carlsson B, Nilsson Y, et al (1998). Differential response of estrogen receptor alpha and estrogen receptor beta to partial estrogen agonists/antagonists. Mol Pharmacol, $\mathbf{5 4}, 105-12$.

Berman HM, Westbrook J, Feng Z, et al (2000). The Protein Data Bank. Nucleic Acids Res, 28, 235-42.

Bollig-Fischer A, Thakur A, Sun Y, et al (2012). The Predominant Proteins that React to the MC-20 Estrogen Receptor Alpha Antibody Differ in Molecular Weight between the Mammary Gland and Uterus in the Mouse and Rat. Int J Biomed Sci, 8, 51-63.

Brzozowski AM, Pike AC, Dauter Z, et al (1997). Molecular basis of agonism and antagonism in the oestrogen receptor. Nature, 389, 753-8.

Cao X, Jiang J, Zhang S, et al (2013). Discovery of natural estrogen receptor modulators with structure-based virtual screening. Bioorg Med Chem Lett, 23, 3329-33.

Chakraborty S, Cole S, Rader N, et al (2012). In silico design of peptidic inhibitors targeting estrogen receptor alpha dimer interface. Mol Divers, 16, 441-51.

Chitrala KN, Yeguvapalli S (2013). Prediction and analysis of ligands against estrogen related receptor alpha. Asian Pac J Cancer Prev, 14, 2371-5.

Czeczuga-Semeniuk E, Jarzabek K, Lemancewicz D, et al (2009). The vitamin A family can significantly decrease the expression of ERbeta of ERs positive breast cancer cells in the presence or absence of ER ligands and paclitaxel. Gynecol Endocrinol, 25, 287-93.

D'Amelio P, Isaia GC (2013). The use of raloxifene in osteoporosis treatment. Expert Opin Pharmacother, 14, 949-56.

de Villiers TJ, Gass ML, Haines CJ, et al (2013). Global Consensus Statement on menopausal hormone therapy. Maturitas, 74, 391-2.

Eliassen AH, Hendrickson SJ, Brinton LA, et al (2012). Circulating carotenoids and risk of breast cancer: pooled analysis of eight prospective studies. J Natl Cancer Inst, 104, 1905-16.

Frasor J, Barnett DH, Danes JM, et al (2003). Response-specific and ligand dose-dependent modulation of estrogen receptor (ER) alpha activity by ERbeta in the uterus. Endocrinol, 144, 3159-66.

Gangloff M, Ruff M, Eiler S, et al (2001). Crystal structure of a mutant hERalpha ligand-binding domain reveals key structural features for the mechanism of partial agonism. $J$ Biol Chem, 276, 15059-65.

Gaudet P, Lane L, Fey P, et al (2009). Collaborative annotation of genes and proteins between UniProtKB/Swiss-Prot and dictyBase. Database (Oxford), 2009, 16.

Hendrickson SJ, Hazra A, Chen C, et al (2012). beta-Carotene 15,15 '-monooxygenase 1 single nucleotide polymorphisms in relation to plasma carotenoid and retinol concentrations in women of European descent. Am J Clin Nutr, 96, 1379-89.

Illera JC, Perez-Alenza MD, Nieto A, et al (2006). Steroids and receptors in canine mammary cancer. Steroids, 71, 541-8. 
Kuiper G, Carlsson B, Grandien K, et al (1997). Comparison of the ligand binding specificity and transcript tissue distribution of estrogen receptors alpha and beta. Endocrinol, 138, 863-70.

Kumar R, Thompson EB (1999). The structure of the nuclear hormone receptors. Steroids, 64, 310-9.

Kumar R, Zakharov MN, Khan SH, et al (2011). The dynamic structure of the estrogen receptor. J Amino Acids, 2011, 812540.

LaFrate AL, Carlson KE, Katzenellenbogen JA (2009). Steroidal bivalent ligands for the estrogen receptor: design, synthesis, characterization and binding affinities. Bioorg Med Chem, 17, 3528-35.

Leinonen R, Nardone F, Zhu W, et al (2006). UniSave: the UniProtKB sequence/annotation version database. Bioinformatics, 22, 1284-5.

Lewis DF, Ogg MS, Goldfarb PS, et al (2002). Molecular modelling of the human glucocorticoid receptor (hGR) ligand-binding domain (LBD) by homology with the human estrogen receptor alpha (hERalpha) LBD: quantitative structure-activity relationships within a series of CYP3A4 inducers where induction is mediated via hGR involvement. J Steroid Biochem Mol Biol, 82, 195-9.

Li X, Huang J, Yi P, et al (2004). Single-chain estrogen receptors (ERs) reveal that the ERalpha/beta heterodimer emulates functions of the ERalpha dimer in genomic estrogen signaling pathways. Mol Cell Biol, 24, 7681-94.

Madeira KP, Daltoe RD, Sirtoli GM, et al (2012). Comparison of immunohistochemical analysis with estrogen receptor SP1 and 1D5 monoclonal antibodies in breast cancer. Pathol Res Pract, 208, 657-61.

Maggiolini M, Bonofiglio D, Marsico S, et al (2001). Estrogen receptor alpha mediates the proliferative but not the cytotoxic dose-dependent effects of two major phytoestrogens on human breast cancer cells. Mol Pharmacol, 60, 595-602.

Meshram RJ, Bhiogade NH, Gacche RN, et al (2012). Virtual screening and docking exploration on estrogen receptor: An in silico approach to decipher novel anticancer agents. Indian J Biotechnol, 11, 389-95.

Millanta F, Calandrella M, Bari G, et al (2005). Comparison of steroid receptor expression in normal, dysplastic, and neoplastic canine and feline mammary tissues. Res Vet Sci, 79, 225-32.

Nam K, Marshall P, Wolf RM, et al (2003). Simulation of the different biological activities of diethylstilbestrol (DES) on estrogen receptor alpha and estrogen-related receptor gamma. Biopolymers, 68, 130-8.

Nam KH, Huang Q, Ke A (2012). Nucleic acid binding surface and dimer interface revealed by CRISPR-associated CasB protein structures. FEBS Lett, 586, 3956-61.

Nose T, Tokunaga T, Shimohigashi Y (2009). Exploration of endocrine-disrupting chemicals on estrogen receptor alpha by the agonist/antagonist differential-docking screening (AADS) method: 4-(1-adamantyl)phenol as a potent endocrine disruptor candidate. Toxicol Lett, 191, 33-9.

Osborne CK, Zhao H, Fuqua SA (2000). Selective estrogen receptor modulators: structure, function, and clinical use. $J$ Clin Oncol, 18, 3172-86.

Pieper U, Eswar N, Braberg H, et al (2004). MODBASE, a database of annotated comparative protein structure models, and associated resources. Nucleic Acids Res, 32, 217-22.

Pike AC, Brzozowski AM, Hubbard RE, et al (1999). Structure of the ligand-binding domain of oestrogen receptor beta in the presence of a partial agonist and a full antagonist. EMBO $J, \mathbf{1 8}, 4608-18$.

Rehm S, Solleveld HA, Portelli ST, et al (2007). Histologic changes in ovary, uterus, vagina, and mammary gland of mature beagle dogs treated with the SERM idoxifene. Birth Defects Res B Dev Reprod Toxicol, 80, 225-32.

Rustici G, Kolesnikov N, Brandizi M, et al (2013). ArrayExpress update--trends in database growth and links to data analysis tools. Nucleic Acids Res, 41, 987-90.

Rybalchenko V, Grillo MA, Gastinger MJ, et al (2009). The unliganded long isoform of estrogen receptor beta stimulates brain ryanodine receptor single channel activity alongside with cytosolic Ca2+. J Recept Signal Transduct Res, 29, 326-41.

Schnell S, Mendoza C (2001). A fast method to estimate kinetic constants for enzyme inhibitors. Acta Biotheor, 49, 109-13.

Shiau AK, Barstad D, Loria PM, et al (1998). The structural basis of estrogen receptor/coactivator recognition and the antagonism of this interaction by tamoxifen. Cell, $\mathbf{9 5}$, 927-37.

Sievers F, Wilm A, Dineen D, et al (2011). Fast, scalable generation of high-quality protein multiple sequence alignments using Clustal Omega. Mol Syst Biol, 7, 539.

Stump AL, Kelley KW, Wensel TM (2007). Bazedoxifene: a third-generation selective estrogen receptor modulator for treatment of postmenopausal osteoporosis. Ann Pharmacother, 41, 833-9.

Suganya J, Radha M, Naorem DL, et al (2014). In Silico docking studies of selected flavonoids-- natural healing agents against breast cancer. Asian Pac J Cancer Prev, 15, 8155-9.

Thompson JD, Higgins DG, Gibson TJ (1994). CLUSTAL W: improving the sensitivity of progressive multiple sequence alignment through sequence weighting, position-specific gap penalties and weight matrix choice. Nucleic Acids Res, 22, 4673-80.

Toniti W, Suthiyotha N, Puchadapirom P, et al (2011). Binding capacity of ER-alpha ligands and SERMs: comparison of the human, dog and cat. Asian Pac J Cancer Prev, 12, 2875-9.

Touraine P (2003). [SERMs and uterus]. Ann Med Interne (Paris), 154, 103-8.

Tremollieres F, Lopes P (2002). [Specific estrogen receptor modulators (SERMs)]. Presse Med, 31, 1323-8.

UniProt C (2014). Activities at the Universal Protein Resource (UniProt). Nucleic Acids Res, 42, 191-8.

Xu CY, Jiang ZN, Zhou Y, et al (2013). Estrogen receptor alpha roles in breast cancer chemoresistance. Asian Pac J Cancer Prev, 14, 4049-52.

Zhang X, Spiegelman D, Baglietto L, et al (2012). Carotenoid intakes and risk of breast cancer defined by estrogen receptor and progesterone receptor status: a pooled analysis of 18 prospective cohort studies. Am J Clin Nutr, 95, 713-25. 